\title{
ЗЕРНООЧИСТИТЕЛЬНЫЕ МАШИНЫ ПАЗМАН
}

\author{
В.А. Николаев (фото)
}

д.т.н., профессор кафедры строительных и дорожных машин ФГБОУ ВО Ярославский государственный технический университет, г. Ярославль

И.В. Кряклина

к.т.н., доцент, доцент кафедры механизации сельскохозяйственного производства ФГБОУ ВО Ярославская ГСХА, г. Ярославль

Бо́льшая часть зерноочистительных машин оснащена прямоугольными решётами. Решётному стану обычно придают колебания, условно параллельные поверхностям решёт. Перемещение частицы при таких колебаниях решета подробно теоретически и экспериментально исследованы [1, с. 242-244; 2, с. 345-347]. Основным не-

Зерноочистительная машина, перевёрнутый усечённый конус, вертикально

колеблющееся решето, траектория зерновки, взаимодействие зерновки с решетом, параметры первого взаимодействия

Grain cleaning machine, inverted flattened cone, vertically varying sieve, trajectory of the Bruchus, interaction of the Bruchus with the sieve, parameters

of the first interaction достатком этих зерноочистительных машин является ограниченная пропускная способность, обусловленная логическим противоречием. Оно заключается в том, что количество очищаемого материала на решете уменьшается, а ширина решета остаётся неизменной.

Для качественного разделения сортируемого материала необходимо, чтобы он располагался на решете в один слой. Для этого ограничивают подачу на него очищаемого материала. При этом значительная часть решета работает неэффективно, так как только часть его поверхности покрыта очищаемым материалом. Чтобы повысить эффективность работы зерноочистительных машин, решёта сдваивают и располагают в два или три яруса. Увеличивают подачу на верхние решёта так, чтобы приблизительно половина сортируемого материала отделялась на первом решете, а оставшийся материал - на втором. Но при этом снижается качество работы зерноочистительной машины, так как первое нижнее решето оказывается недогруженным, работает неэффективно. Второе верхнее решето также работает недостаточно эффективно, так как нельзя допустить попадания полноценного очищаемого материала в крупные отходы.

Поскольку по мере прохождения материала сквозь решето количество очищаемого материала на решете уменьшается, рационально было бы применять трапецеидальное решето. Однако конструктивная реализация зерноочистительной машины с трапецеидальными решётами затруднена. Так как свойства очищаемых материалов различные, то и количество материала, проходящего сквозь решето по мере его перемещения по трапецеидальному решету, будет различным. Следовательно, возникает необходимость иметь набор трапецеидальных решёт, у которых основания трапеций будут различной длины. Сложно приспособить зерноочистительные машины под набор таких решёт, хотя варианты конструктивного решения проблемы не исключены. 
Дальнейшим развитием идеи применения трапецеидальных решёт является реализация зерноочистительной машины с решетом, представляющим перевёрнутый усечённый конус, совершающий вертикальные колебания. Если несколько трапецеидальных решёт изогнуть и соединить, то получится перевёрнутый усечённый конус. Взаимодействие зерновки с вертикально колеблющимся решетом не исследовано и вызывает теоретический и практический интерес.

На рисунках 1 и 2 представлена конструктивная компоновка полуавтоматической зерноочистительной машины с вертикально колеблющимся решетом, схема работы и регулирования [3,

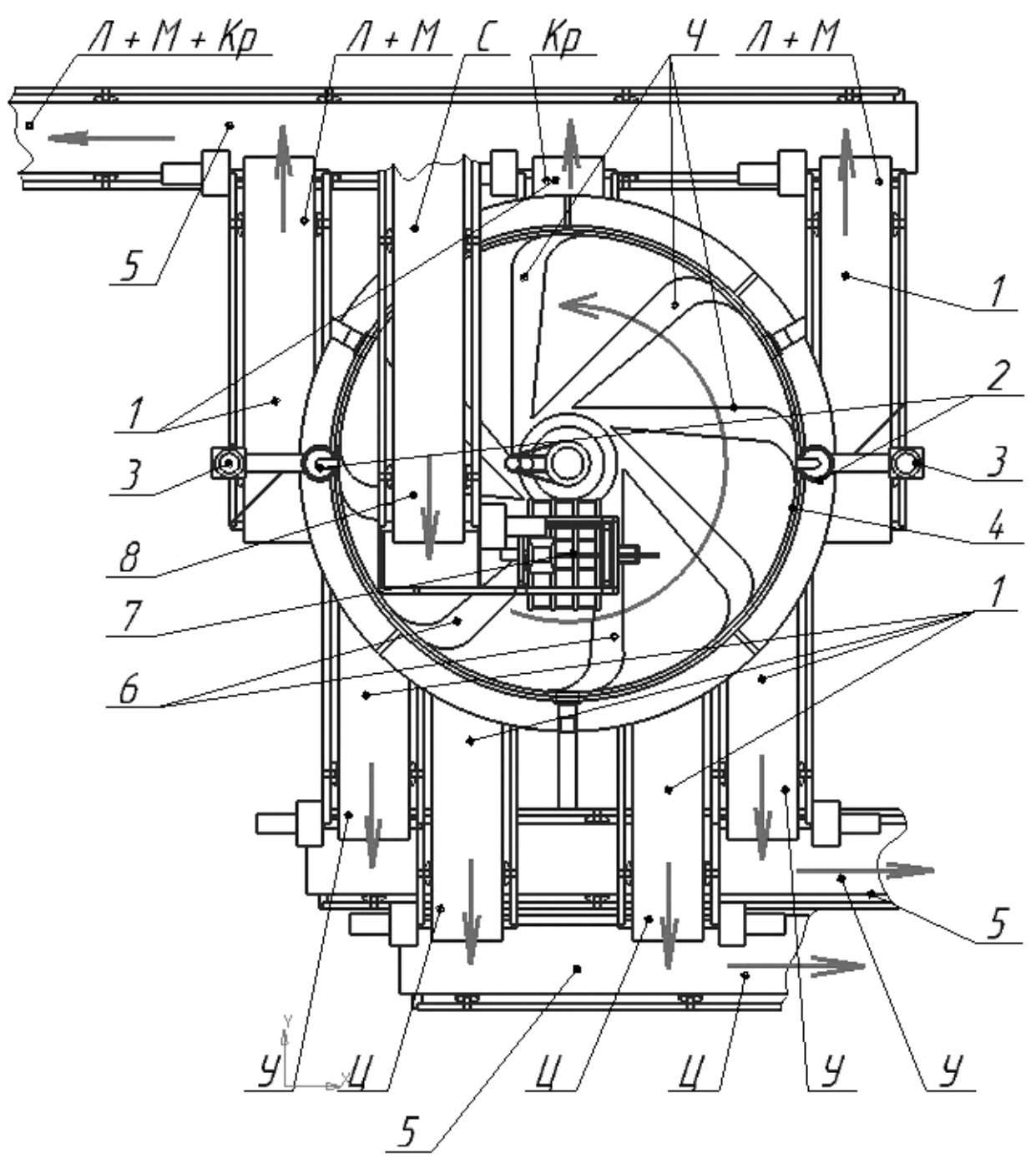

1 - транспортёр; 2 - привод карусели; 3 - привод подъёмника; 4 - стенка бункера;

5 - конвейер; 6 - пневмоканал; 7 - пробник; 8 - транспортёр зернового вороха.

Рисунок 1 - Конструктивная компоновка полуавтоматической зерноочистительной машины с вертикально колеблющимся решетом, вид сверху

с. 1-20]. Корпус карусели 6 (рис. 2) опирается на стойки 1 посредством роликов верхних. На него надет и приклеен резиновый бандаж, с которым соприкасаются два привода карусели 2 (рис. 1). На одной из стоек установлен электроуправляемый тормоз карусели. На стойках установлены два привода подъёмника 3. Вверху к корпусу карусели присоединены пневмоканалы 6, на схождении которых, сверху, расположены: привод пневморегулятора 7 (рис. 2), управляющий пневморегулятором; привод конуса бункера 8, управляющий конусом бункера 5; электродвига- 


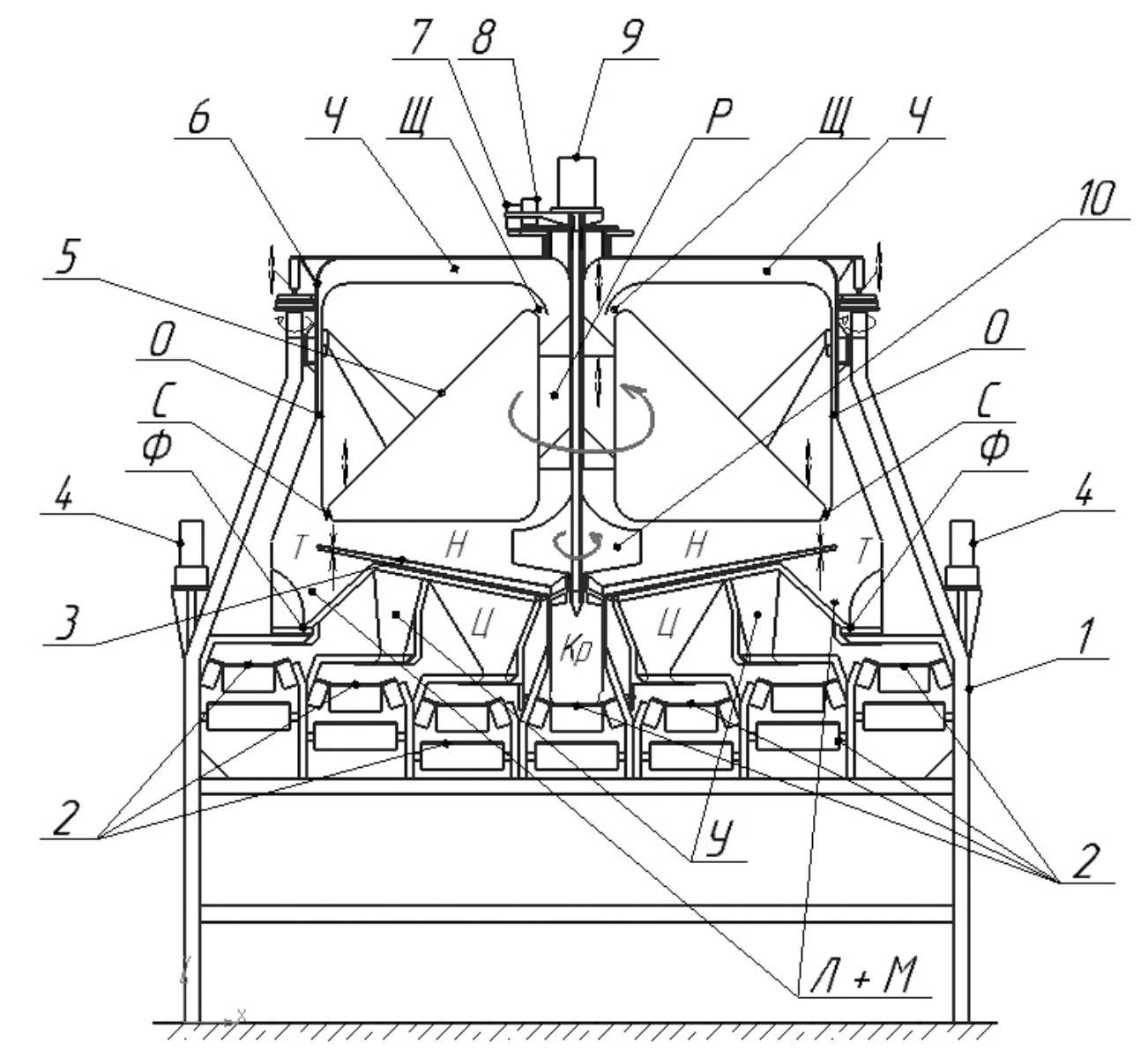

1 - стойка; 2 - транспортёр; 3 - остов решёт; 4 - привод подъёмника; 5 - конус бункера; 6 - корпус карусели; 7 - привод пневморегулятора; 8 - привод конуса бункера; 9 - электродвигатель привода вентилятора; 10 - крыльчатка.

Рисунок 2 - Схема работы и регулирования полуавтоматической зерноочистительной машины с вертикально колеблющимся решетом

тель привода вентилятора 9, соединённый валом, проходящим внутри привода конуса бункера, с крыльчаткой 10. К конусу бункера приварены державки, скользящие по направляющим. Направляющие приварены к стенке бункера 4 (рис. 1), соединённой в нескольких местах связками с корпусом карусели.

На раме транспортёров установлены транспортёры 1 и 2 (рис. 2): малых и лёгких примесей «Л+М», ущербных зёрен «У», целых зёрен «Ц» и посередине - транспортёр крупных примесей «Кр». Над транспортёрами малых и лёгких примесей, транспортёрами ущербных зёрен, транспортёрами целых зёрен имеются сбрасыватели. Под сходами с транспортёров малых и лёгких примесей, транспортёра крупных примесей расположен конвейер 5 примесей «Л+M+Кр». Под сходами с транспортёров ущербных зёрен расположен конвейер 5 ущербных зёрен «У». Под сходами с транспортёров целых зёрен расположен конвейер 5 целых зёрен «Ц». С транспортёров малых и лёгких примесей, транспортёра крупных примесей, транспортёров ущербных зёрен, транспортёров целых зёрен свисают фартуки. Кроме этого, на раме транспортёров расположена стойка опорных роликов, на которой установлены опорные ролики. На них опираются фигурные тарелки (рис. 2) с лотком крупных примесей «Кр», кольцевые тарелки: с лотком целых зёрен «Ц», лотком ущербных зёрен «У», лотком лёгких и малых примесей «Л+М», подпираемым сбоку пружинящим фартуком.

Вверху стойка опорных роликов, присоединённая к перемычке между стойками, имеет шлицевую часть, взаимодействующую со шлицами остова решёт 3 (рис. 2). К остову решёт посред- 
ством магнитов присоединены: решето малых примесей, решето ущербных зёрен и решето целых зёрен, которые имеют форму перевёрнутых усечённых конусов. К остову решёт приварена по окружности дорожка, опирающаяся на ролик нижний.

Над корпусом карусели расположен транспортёр зернового вороха 8 (рис. 1) с присоединёнными к нему рельсами. Пробник 7 установлен на рельсах. На раме пробника установлен блок управления и контроля (БУК). На полуавтоматической зерноочистительной машине расположены также: датчики уровня, датчики ударного воздействия, путевые датчики, датчик давления, блок управления и сигнализации (БУС).

В результате теоретических исследований установлено: количество циклов колебания решёт $k=8$, угловая скорость корпуса полуавтоматической зерноочистительной машины $\omega_{\kappa}=4,05$ рад/с, период колебания решёт $\tau_{\mathrm{p}}=0,194 \mathrm{c}$, общее перемещение зерновки вниз за один цикл колебания решёт $s_{\Sigma}=19,9$ мм. Отсюда перемещение зерновки вниз по решётам за один оборот корпуса полуавтоматической зерноочистительной машины:

$$
\begin{gathered}
s_{\Sigma 1 \text { об }}=k s_{\Sigma} ; \\
s_{\sum_{1 \text { oб }}}=8 \cdot 19,9=159,2 \text { мм. }
\end{gathered}
$$

За одну секунду зерновка переместится вниз по образующей решёт на расстояние

$$
\begin{gathered}
s_{\Sigma 1 c}=\frac{s_{\Sigma 1 o \sigma}}{\tau_{p}} ; \\
s_{\Sigma 1 c}=\frac{19,9}{0,194} \approx 102 \mathrm{MM} / \mathrm{c} .
\end{gathered}
$$

Длина образующей решёт, на которой происходит сепарация зернового вороха, $l_{o}=723$ мм. Если частица зернового вороха перемещается строго по образующей решёт, время её перемещения до схода с последнего решета:

$$
\begin{gathered}
\tau_{\mathrm{o}}=\frac{l_{o}}{s_{\Sigma 1 c}} ; \\
\tau_{\mathrm{o}}=\frac{723}{102} \approx 7,1 \mathrm{c} .
\end{gathered}
$$

Примем толщину условного слоя зернового вороха на решётах равной ширине зерновки, $b_{\text {зв }}=3$ мм. Допустим, что условный слой состоит из одних зерновок, а зерновки прижаты друг к другу после падения на решето, то есть «лежат на боку». Толщина зерновки тритикале 2 мм. Тогда количество зерновок, которое разместится на периферии решёт:

$$
n_{p}=\frac{p}{0002}
$$

где условный периметр периферийного решета $p=2 \pi r_{\text {п' }}$ соответствующий совокупности точек касания зерновок и решета, $r_{\text {п }}=0,9 \mathrm{M}$.

$$
n_{p}=\frac{2 \cdot 3,14 \cdot 0,9}{0,002}=2826 \text { шт. }
$$

Длина зерновки тритикале 8 мм. За одну секунду попадёт условных рядов зерновок на периферию решета:

$$
\begin{gathered}
n_{\text {рядов }}=\frac{s_{\Sigma 1 c}}{8} ; \\
n_{\text {рядов }}=\frac{102}{8}=12,75 .
\end{gathered}
$$

За одну секунду пройдёт зерновок по периферии решета:

$n_{\text {з } p}=n_{p} n_{\text {рядов }} ; n_{\text {зр }}=2826 \cdot 12,75 \approx 36031$ шт.

Пропускная способность полуавтоматической зерноочистительной машины:

$$
\begin{gathered}
Q=n_{\text {зр }} m ; \\
Q=36031 \cdot 3 \cdot 10^{-5}=1,08 \text { кг/с } \approx 3890 \text { кг } / \text { ч. }
\end{gathered}
$$

Рассчитаем основные параметры модельного ряда полуавтоматических зерноочистительных машин. Для этого следует решить обратную задачу: по заданной пропускной способности определить параметры машин. Уменьшать пропускную способность нерационально, так как уменьшится длина образующей решёт. Это может ухудшить качество сепарации зернового вороха. Так как некоторые данные приведённого расчёта пропускной способности полуавтоматической зерноочистительной машины взяты условно, а полученная в результате расчётов её пропускная способность $Q \approx 1$ кг/с, то присвоим машине с рассчитанными параметрами марку ПАЗМАН-1 (полуавтоматическая зерноочистительная машина Николаева).

Для увеличения пропускной способности следует увеличить габариты машины. При этом увеличится как периметр, так и длина образующей решёт. Следует увеличивать и внутренний радиус $r$, так как необходим больший объём подаваемого для очистки воздуха. Однако внутренний радиус $r$, где поток воздуха входит в пространство между решётами и нижней поверхностью конуса бункера, будет увеличиваться меньше, чем радиус совокупности точек предполагаемого падения зерновок на решето $r_{\text {п }}$. Поскольку увеличится длина образующей решёт, качественную сепарацию можно обеспечить, располагая зерновки на периферии решёт не в один слой. Для расчёта введём понятие «приведенные параметры». Приведенные параметры - это такие параметры полуавтоматической зерноочистительной машины, которые были бы, если бы зерновки на периферии решёт располагались в один слой.

Чтобы вычислить истинные величины параметров, необходимо ввести коэффициенты приведения $k_{n p}$. Физический смысл коэффициен- 
тов приведения заключается в степени влияния соотношения приведенных длин образующих решёт при увеличении пропускной способности машины на количество слоёв зерновок. То есть длину образующей решёт машины ПАЗМАН-1 $l_{\text {опАзмАн-1 }}=0,723$ м принимаем за эталон. При увеличении пропускной способности машины увеличивается соотношение приведенных длин образующих решёт. Количество слоёв на периферии решёт следует увеличивать пропорционально соотношению приведенных длин образующих решёт, но с учётом коэффициента приведения. Для расчёта параметров машин примем ориентировочные коэффициенты приведения, которые следует уточнить путём проведения экспериментов. Критерием является качественная очистка зерна при оптимальной загрузке решёт. Последовательность расчёта:

- пропускная способность зерновок в секунду

$$
n_{3} p=\frac{Q}{m}
$$

- приведенное количество зерновок, которое разместится на периферии решёт

$$
n_{p_{\text {прив }}}=\frac{n_{3} p}{n_{\text {рядов }}}=\frac{n_{3} p}{12,75} ;
$$

- приведенный условный периметр периферийного решета

$$
p_{\text {nрuв }}=0,002 n_{p^{\prime}}
$$

- приведенный радиус совокупности точек предполагаемого падения зерновок на решето

$$
r_{\text {П прив }}=\frac{p}{2 \pi}=\frac{p}{6,28} ;
$$

- приведенная длина образующей решёт, на которой происходит сепарация,

$$
l_{\text {ориив }}=\frac{r_{\Pi} r}{\cos \alpha}=\frac{r_{\Pi} \quad 0,25}{0899} ;
$$

- количество слоёв зерновок

$$
k_{p_{3}}=\frac{l_{\text {onpus }}}{l_{\text {oпA3MAH-1 }}} k_{n p^{\prime}} ;
$$

- количество зерновок, которое разместится на периферии решёт

$$
n_{p}=k_{p_{3}} n_{p \text { привi }}
$$

- условный периметр периферийного решета

$$
p=0,002 n_{p} \text {; }
$$

- радиус совокупности точек предполагаемого падения зерновок на решето

$$
r_{\Pi}=\frac{p}{2 \pi} ;
$$

- длина образующей решёт, на которой происходит сепарация,

$$
l_{o}=\frac{r_{\mathrm{\Pi}} r}{\cos \alpha} ;
$$

- время перемещения зерновки по решётам

$$
\tau_{\mathrm{o}}=\frac{l_{o}}{s_{\Sigma 1 c}} ;
$$

- площадь кольцевого сечения, сквозь которое движется поток воздуха

$$
S=p h_{\text {mini }}
$$

- объём подачи воздуха крыльчаткой

\begin{tabular}{|c|c|c|c|c|c|c|c|c|c|}
\hline \multirow[t]{2}{*}{ Марка } & $\begin{array}{c}\text { Про- } \\
\text { пускная } \\
\text { способ- } \\
\text { ность, } Q\end{array}$ & $\begin{array}{c}\text { Про- } \\
\text { пускная } \\
\text { способ- } \\
\text { ность }\end{array}$ & $\begin{array}{c}\text { К-во } \\
\text { зерно- } \\
\text { вок }\end{array}$ & $\begin{array}{l}\text { Пери- } \\
\text { метр, } p\end{array}$ & $\begin{array}{c}\text { Радиус, } \\
r_{n}\end{array}$ & $\begin{array}{l}\text { Длина } \\
\text { обр., } l_{o}\end{array}$ & $\begin{array}{c}\text { Время, } \\
\tau_{o}\end{array}$ & $\begin{array}{l}\text { Пло- } \\
\text { щадь } \\
\text { к.с., } S\end{array}$ & $\begin{array}{c}\text { Подача } \\
\text { воздуха, } \\
Q_{6 к}\end{array}$ \\
\hline & $\mathrm{K} \Gamma / \mathrm{C}$ & $T / 4$ & шт. & $M$ & $M$ & $M$ & C & KB. M & куб. м/с \\
\hline ПАЗМАН-1 & 1,08 & 3,888 & 2823 & 5,647 & 0,9 & 0,722 & 7,07 & 0,169 & 1,69 \\
\hline ПАЗМАН-2 & 2 & 7,2 & 7696 & 7,104 & 1,131 & 0,980 & 9,61 & 0,213 & 2,13 \\
\hline ПАЗМАН-З & 3 & 10,8 & 15568 & 7,902 & 1,258 & 1,121 & 11 & 0,237 & 2,37 \\
\hline ПАЗМАН-4 & 4 & 14,4 & 23601 & 9,267 & 1,475 & 1,363 & 13,36 & 0,278 & 2,78 \\
\hline ПАЗМАН-5 & 5 & 18 & 29904 & 11,427 & 1,819 & 1,746 & 17,11 & 0,342 & 3,42 \\
\hline ПАЗМАН-10 & 10 & 36 & 93338 & 14,645 & 2,332 & 2,316 & 22,7 & 0,439 & 4,39 \\
\hline
\end{tabular}

$$
Q_{\text {в }}=S v_{\mathrm{B}} \text {. }
$$

Результаты расчётов параметров модельного ряда машин показаны в таблице 1.

Мощность двигателей привода корпуса карусели, приводов подъёмника - 1,1 кВт, привода пневморегулятора и привода конуса бункера 0,65 кВт. Мощность электропривода вентилятора, соответственно маркам: 2,8 кBт, 3,18 кBт, 3,35 кBт, 3,6 кBт, 4 кBт, 4,6 кBт.

Таблица 1 - Параметры модельного ряда полуавтоматических зерноочистительных машин ПАЗМАН

\section{Bывод}

Получена конструктивная компоновка полуавтоматической зерноочистительной машины с вертикально колеблющимися решетами в форме перевёрнутого усечённого конуса. Определены основные параметры модельного ряда полуавтоматических зерноочистительных машин ПАЗМАН. 


\section{Лumepamypa}

1. Сельскохозяйственные машины. Теория и технологический расчёт [Текст] / под ред. Б.Г. Турбина. Изд. 2-е, перераб. и доп. - Л.: «Машиностроение», 1967. - 584 с.

2. Клёнин, Н.И. Сельскохозяйственные машины [Текст] / Н.И. Клёнин, С.Н. Киселёв, А.Г. Левшин. - М.: КолосС, 2008. - 816 с.

3. Пат. 2623473 Российская Федерация. Полуавтоматическая зерноочистительная машина [Текст] / Николаев В.А.; заявитель и патентообладатель ФГБОУ ВО «Ярославская государственная сельскохозяйственная академия» - № 2016108555; заявл. 23.04.2015; опубл. 20.06.2017, Бюл. № 18.

\section{References}

1. Sel'skohozjajstvennye mashiny. Teorija i tehnologicheskij raschjot [Tekst] / pod red. B.G. Turbina. - Izd. 2-e, pererab. i dop. - L.: «Mashinostroenie», 1967. - $584 \mathrm{~s}$.

2. Klenin, N.I. Sel'skohozjajstvennye mashiny [Tekst] / N.I. Klenin, S.N. Kiselev, A.G. Levshin. - M.: KolosS, 2008. $-816 \mathrm{~s}$.

3. Pat. 2623473 Rossijskaja Federacija. Poluavtomaticheskaja zernoochistitel'naja mashina [Tekst] / Nikolaev V.A.; zajavitel'i patentoobladatel'FGBOU VO «Jaroslavskaja gosudarstvennaja sel'skohozjajstvennaja akademija» - № 2016108555; zajavl. 23.04.2015; opubl. 20.06.2017, Bjul. № 18.

\section{ОБЫЯВЛЕНИЕ}

В издательстве ФГБОУ ВО Ярославская ГСХА в 2019 году вышла МОНОГРАФИЯ

\section{В.В. ШМИГЕЛЯ, А.С. УГЛОВСКОГО}

\section{СЕПАРАЦИЯ СЕМЯН ОВОЩНЫХ КУЛЬТУР В ЭЛЕКТРОСТАТИЧЕСКОМ ПОЛЕ}

В монографии рассматриваются проблемы сортирования семян овощных культур в электростатическом поле. Рассматриваются вопросы теории, методики исследований, результаты исследований, экономическое обоснование. Приводятся разработанные установки для сортировки семян овощных культур в электростатическом поле; исследуются: свойства семян овощных культур семейства тыквенные, поведение семян в электростатическом поле, электростатическое поле с частицами и без, результаты оптимизации автоматизированной установки по сепарации семян огурца.

Монография предназначена для студентов старших курсов (бакалавров, магистров), аспирантов, а также инженеров, агрономов и научных работников, занимающихся разработкой электрических сепараторов семян овощных культур.

УДК 631.362:621.319; ББК 22.33; ISВN 978-5-98914-221-7; 160 СТР.

ПО ВОПРОСАМ ПРИОБРЕТЕНИЯ ОБРАЩАТЬСЯ ПО АДРЕСУ: 150042, г. Ярославль, Тутаевское шоссе, 58, ФГБОУ ВО Ярославская ГСХА e-mail: e.bogoslovskaya@yarcx.ru 